Review Article

\title{
Chronicity of Hepatotoxicity: A Review
}

Dr. Lalita Bansal ${ }^{1 *}$, Dr. Ashish Dhiman ${ }^{2}$

${ }^{1}$ Medical Officer (OBG) R.H. Kullu Himachal Pradsh, India

${ }^{2}$ Medical Officer (General Surgery), R.H. Kullu Himachal Pradsh, India

\author{
Article History \\ Received: 17.11.2021 \\ Accepted: 12.01.2022 \\ Published: 21.01.2022
}

Journal homepage:

https://www.easpublisher.com

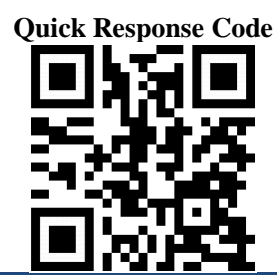

Abstract: Hepatotoxicity is the damage or liver harm as a result of publicity to drugs; it's far an detrimental drug response that can be unusual however serious. The hepatic damage may be categorised into hepatocellular, cholestatic and mixed, as a result of boom in alanine aminotransferase and alkaline phosphatase than top restrict of normal. The danger elements encompass idiosyncrasy, age, gender, and alcohol consumption, concomitant use of different drugs, preceding or underlying liver disease, genetic and environmental elements. Liver toxicity manifestations are usually followed with the aid of using nonspecific signs consisting of belly pain, jaundice, fever, nausea, vomiting, diarrhea, pruritus and rash. The review gives brief illustration about liver associated injury along with role of antioxidant in oxidative stress.

Keywords: Hepatotoxicity, drug induced liver toxicity, oxidative stress \& antioxidant.

Copyright $\odot \mathbf{2 0 2 2}$ The Author(s): This is an open-access article distributed under the terms of the Creative Commons Attribution 4.0 International License (CC BY-NC 4.0) which permits unrestricted use, distribution, and reproduction in any medium for non-commercial use provided the original author and source are credited.

\section{INTRODUCTION}

\section{Liver}

The liver is the body's most vital organ. It is crucial in the regulation of a variety of physiological functions. It also has a role in metabolism, secretion, and storage, among other things. It has a high ability for detoxication and the creation of beneficial principles. It aids in the body's maintenance, performance, and regulation of homeostasis. It's involved in nearly every metabolic route leading to growth, disease resistance, nutrition delivery, energy provision, and reproduction. It also helps with glucose, protein, and fat metabolism, as well as detoxification, bile secretion, and vitamin storage. Because of its role in removing toxins from the portal circulation, this organ is vulnerable to a series of attacks by foreign compounds, culminating liver failure [1].

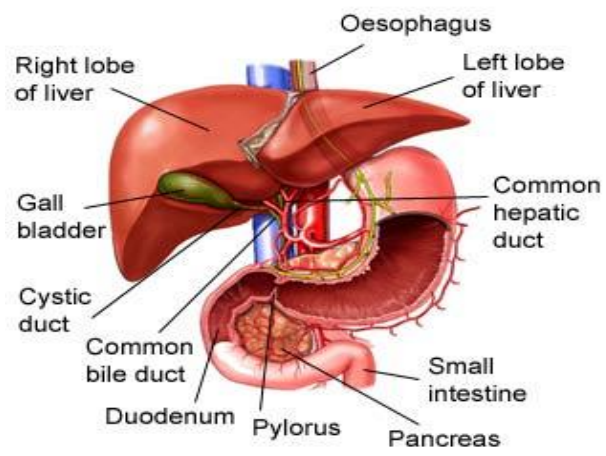

Fig-1: Structure of Liver

\section{Liver Anatomy}

The liver is observed with inside the top proper-hand facet of the stomach below the ribs under the diaphragm. It is a darkish reddish-brown organ that weighs approximately 3 pounds. The liver has a proper lobe and a left lobe. Blood enters the liver from the hepatic artery and the hepatic portal vein and leaves the liver from the hepatic vein. Inside the 2 lobes is a community of tubes, additionally known as the biliary tree that incorporates bile from the liver to the intestine. Bile is a substance that allows deliver away wastes and is wanted for the breakdown and absorption of nutritional fats. Each tube is known as a duct. Smaller ducts connect with large ducts. The large ducts are a part of to shape the hepatic duct. This duct community lets in bile to empty out of the liver [2].

\section{Liver functions}

Liver identifies xenobiotics and metabolize them and lead them to appropriate for elimination. This entails chemical transformation (a) lowering lipid solubility (b) alternate the organic activity. Mainly clean endoplasmic reticulum of liver basically participates in metabolism. It is likewise referred to as as metabolic clearing residence of each exogenous and endogenous substance. (Blumenthal D., et al., 2006) Drug metabolism takes area in 2 phases; Phase I and Phase II. Phase I reactions contain oxidation, reduction, hydrolysis, hydration which makes them water soluble and additionally generate metabolites which might be extra chemically lively and doubtlessly toxic. Phase II 
reactions takes area in cytosol and contain conjugation with endogenous compounds thru transferase enzyme, a set of enzymes. Cytochrome P450 is a enzymes are positioned in endoplasmic reticulum, referred to as cytochrome P 450 terminal oxidase issue of electron shipping chain. It isn't always a unmarried enzyme however includes a own circle of relatives carefully associated with 50 isoforms, 6 of them metabolize $90 \%$ of drugs [3].

\section{Liver disease epidemiology}

Hepatocellular injury is characterised via way of means of enormous elevations withinside the aminotransferases in serum which typically precede elevations in overall bilirubin tiers and alkaline phosphatase tiers. Most accidents arise inside $1 \mathrm{yr}$ of beginning the offending agent. Hepatocellular harm can cause fulminant hepatitis with a corresponding $20 \%$ survival price with supportive care. For the ones sufferers who gift with the aggregate of hepatocellular harm and jaundice, there's a $10 \%$ mortality price. Acarbose, allopurinol, fluoxetine, and losartan are able to inflicting hepatocellular injury [4].

\section{Liver disease}

It is a broad term describing any single number of diseases affecting the liver. Many are accompanied by jaundice caused by increased levels of bilirubin in the system. The bilirubin results from the breakup of the hemoglobin of dead red blood cells; normally, the liver removes bilirubin from the blood and excretes it through bile [5-14].

\begin{tabular}{|l|l|}
\hline Liver disease & Description \\
\hline Hepatitis & $\begin{array}{l}\text { Hepatitis, inflammation of the liver, caused mainly by various viruses but also by some } \\
\text { poisons (e.g. alcohol), autoimmunity (autoimmune hepatitis) or hereditary conditions. } \\
\text { Diagnosis is done by checking levels of Alanine transaminase. }\end{array}$ \\
\hline $\begin{array}{l}\text { Non-alcoholic fatty liver } \\
\text { disease }\end{array}$ & $\begin{array}{l}\text { Non-alcoholic fatty liver disease, a spectrum in disease, associated with obesity and } \\
\text { characterized as an abundance of fat in the liver; may lead to a hepatitis,i.e. } \\
\text { steatohepatitis and/or cirrhosis. }\end{array}$ \\
\hline Cirrhosis & $\begin{array}{l}\text { Cirrhosis is the formation of fibrous tissue in the liver from replacing dead liver cells. } \\
\text { The death of the liver cells can be caused by viral hepatitis, alcoholism or contact with } \\
\text { other liver-toxic chemicals. Diagnosis is done by checking levels of Alanine } \\
\text { transaminase and Asparatine transaminase (SGOT). }\end{array}$ \\
\hline Haemochromatosis & $\begin{array}{l}\text { Haemochromatosis, a hereditary disease causing the accumulation of iron in the body, } \\
\text { eventually leading to liver damage. }\end{array}$ \\
\hline Cancer of the liver & $\begin{array}{l}\text { Cancer of the liver (primary hepatocellular carcinoma or cholangiocarcinoma and } \\
\text { metastatic cancers, usually from other parts of the gastrointestinal tract). }\end{array}$ \\
\hline Wilson's disease & Wilson's disease, a hereditary disease which causes the body to retain copper. \\
\hline Autoimmune & $\begin{array}{l}\text { Primary sclerosing cholangitis, an inflammatory disease of the bile duct, likely } \\
\text { autoimmune in nature. }\end{array}$ \\
\hline Primary biliary cirrhosis & Primary biliary cirrhosis, autoimmune disease of small bile ducts. \\
\hline Budd-Chiari syndrome & Budd-Chiari syndrome, obstruction of the hepatic vein. \\
\hline Gilbert's syndrome & $\begin{array}{l}\text { Gilbert's syndrome, a genetic disorder of bilirubin metabolism, found in about 5\% of } \\
\text { the population. }\end{array}$ \\
\hline $\begin{array}{l}\text { Glycogen storage disease } \\
\text { type II }\end{array}$ & $\begin{array}{l}\text { Glycogen storage disease type II, the build-up of glycogen causes progressive muscle } \\
\text { weakness (myopathy) throughout the body and affects various body tissues, particularly } \\
\text { in the heart, skeletal muscles, liver and nervous system. }\end{array}$ \\
\hline
\end{tabular}

There are also many pediatric liver diseases, including biliary atresia, alpha-1 antitrypsin deficiency, alagille syndrome, and progressive familial intrahepatic cholestasis. Liver illnesses stay one of the most important threats to public fitness and are a international problem. They are specifically as a result of chemical compounds like acetaminophen (in huge doses), extra intake of alcohol, infections and autoimmune disorders. Most of the hepatotoxic chemical compounds harm liver cells specifically via way of means of inducing lipid peroxidation and different oxidative damages [15]. Acetaminophen, a mild analgesic and antipyretic drug, developed in the last century, causes serious liver necrosis in humans and in experimental animals if taken in large doses[16]. While alcohol is one of the main causes of end stage liver disease worldwide, alcoholic liver disease is the second most common reason for liver transplantation in the United States [17]. Due to increased frequency of drinking and change of diet construction, such as the increase of fat content, the incidence of liver diseases has increased in China, becoming another important risk factor for morbidity and mortality in addition to viral hepatitis [18]. The spectrum of alcoholic liver disease ranges from fatty liver to alcoholic hepatitis and ultimately fibrosis and cirrhosis.

In spite of the tremendous advances in modern medicine, there is no effective drug available that stimulates liver function, offer protection to the liver from damage or help to regenerate hepatic cells. It is therefore necessary to search for alternative drugs for 


\section{Types of Hepatotoxicity}

\section{Intrinsic Hepatotoxicity}

One of two major categories of chemicals that can produce dosedependent, hepatic injury, either directly or indirectly via a metabolite, includes the intrinsic or direct (type A) hepatotoxicants. These responses often can be anticipated from the known pharmacology of the drug, are generally detectable in animal models, and occur more frequently or with greater severity when exposure is increased, i.e., with increasing dose Levels or duration of dosing. Salicylates [19] and acetaminophen is examples of analgesics that produce intrinsic liver toxicity. At high blood levels, aspirin can produce hepatocellular injury, confirmed by liver biopsy studies (focalnecrosis), with 10-to40fold elevations for serum transaminases noted. Chemotherapeutic agents often possess predictable, dose-dependent Hepatotoxicity, even though they do not intentionally target slowly dividing hepatocytes [20].

Tetracycline, methotrexate, mercaptopurine and possibly suldinac[21] are other examples of direct hepatotoxins. Intrinsic hepatotoxins produce injury in a large percentage of exposed individuals after a short fixed latent period either by direct, non selective physicochemical distortion of hepatocytes or by indirect presence with specific metabolic processes leading to structural damage[22].This type of toxicity can be alleviated by dose reduction in patient populations.

\section{Idiosyncratic Hepatotoxicity}

Although number of drug like antineoplastic agents. Exhibit intrinsic toxicity in man or animals, most hepatotoxic drug reactions in humans are considered to be idiosyncratic [23], due to unusual susceptibility of an individual. Occurring at healing doses after a variable latent period, those responses are characterized via way of means of an prevalence of hepatic damage this is very low in frequency inside a population, dose independent, and now no longer reproducible in experimental animals [24]. Due to their low incidence, idiosyncratic responses are generally not detected in the drug development process after a large number of patients have been treated. Although rare, serious adverse liver responses may include fulminant hepatitis and cholestasis. These account for many drug induced deaths worldwide. Drugs withdrawn from the market due to idiosyncratic drug reactions, including or due solely to hepatotoxicity, include benoxaprofen, ibufenac, temafloxacin, tenilicacid, nomifensine, and perhexilene $[25,26]$.

\section{Aberrant metabolism based responses leading to the accumulation} of toxic metabolites insusceptible individuals

\section{Hypersensitivity or immune-based toxicity}

Etiologically, these reactions are of two major types: Additional mechanisms may include abnormal receptor sensitivity, latent biochemical abnormalities, or multi factorial causes Almost all hepatotoxic reactions to antibacterials or NSAID sespecially of the indole, pyrazole and propionic acid classes are idiosyncratic. Mechanisms may be primarily metabolite dependent (isoniazid, diclofenac), hypersensitivity mediated (betalactams, sulindac), or both (sulfonamides, erythromycin derivatives.Some notable histamine receptor antagonists $\left(\mathrm{H}_{2}\right.$ and a number of anti depressants are associated with hepatic idiosyncratic reactions, presumably mediated via chemically reactive metabolites [28-29].

\section{Immune system- based toxicity}

Immune based injuries represent the other major mechanism for idiosyncratic responses in humans. Auto immunity triggered by xenobiotics involves the modification of host tissues or immune cells by the chemical so that self antigens are erroneously targeted; drug hypersensitivity or allergy refers to a situation where the immune system responds in an exaggerated or inappropriate manner by one of four mechanisms. Most autoimmune diseases are associated with specific alleles of the major histocompatibility complex (MHC) class II genes (Fronek, et al., 1991). The high level of polymorphism that is characteristic of the MHC genes may lead to sub populations of individuals who are highly immune to responses toward drugrelated antigens. Four major categories of drugs known to cause autoimmune responses include hydrazines, derivatives of aromatic amines, sulfhydryl containing compounds, and compounds with a phenol ring. Specific examples of drugs known or suspected of causing hepatitis via an autoimmune mechanism include methyldopa, oxypehnisatin, isoniazid, nitrofurantoin, clometacin, fenofibrate, papaverine and tienilic acid Although other non genetic factors may be involved in the etiology of altered immune responses, the role of drug metabolism polymorphism leading to bioactivation is an important one. Extra hepatic metabolism of some drugs associated with a generalized type of idiosyncratic drug reaction mediated through the immune system may also involve the liver [29-31].

\section{Mixed or Species-Relevant Toxicity}

Several drugs appear to cause idiosyncratic hepatic injury in humans and yet can also produce hepatotoxicity, perhaps by a different mechanism, in 
animal models at high doses. Thus, the same drug can be an intrinsic hepatotoxicant in one or more animal models and yet cause an idiosyncratic liver response in some humans. Some of the angiotensin converting enzyme inhibitors used for the treatment of hypertension and congestive heart disease fall into this category. Captopril, for example, has been associated with the rare incidence of hepatotoxicity in humans. In mice, acute high doses of captopril cause moderate increases in ALT, decreases in hepatic GSH, and histological evidence of hepatic necrosis with $24 \mathrm{~h}$. Enalapril maleate which has been reported to cause a rare but potentially serious hepatotoxicity in humans was demonstrated by Jurim A Romet and Huang 1992 to produce centrilobular necrosis and significant moderate increases in ALT and AST $24 \mathrm{~h}$ after acute exposure in Fisher 344 rats [32,33].

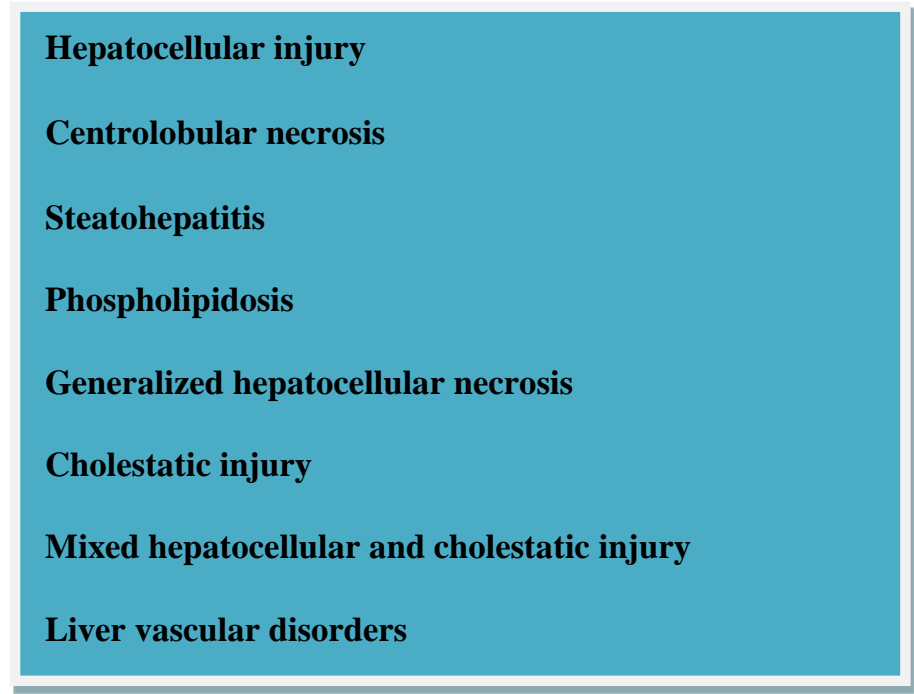

Pattern of Drug Induced Liver Disease [34-38]

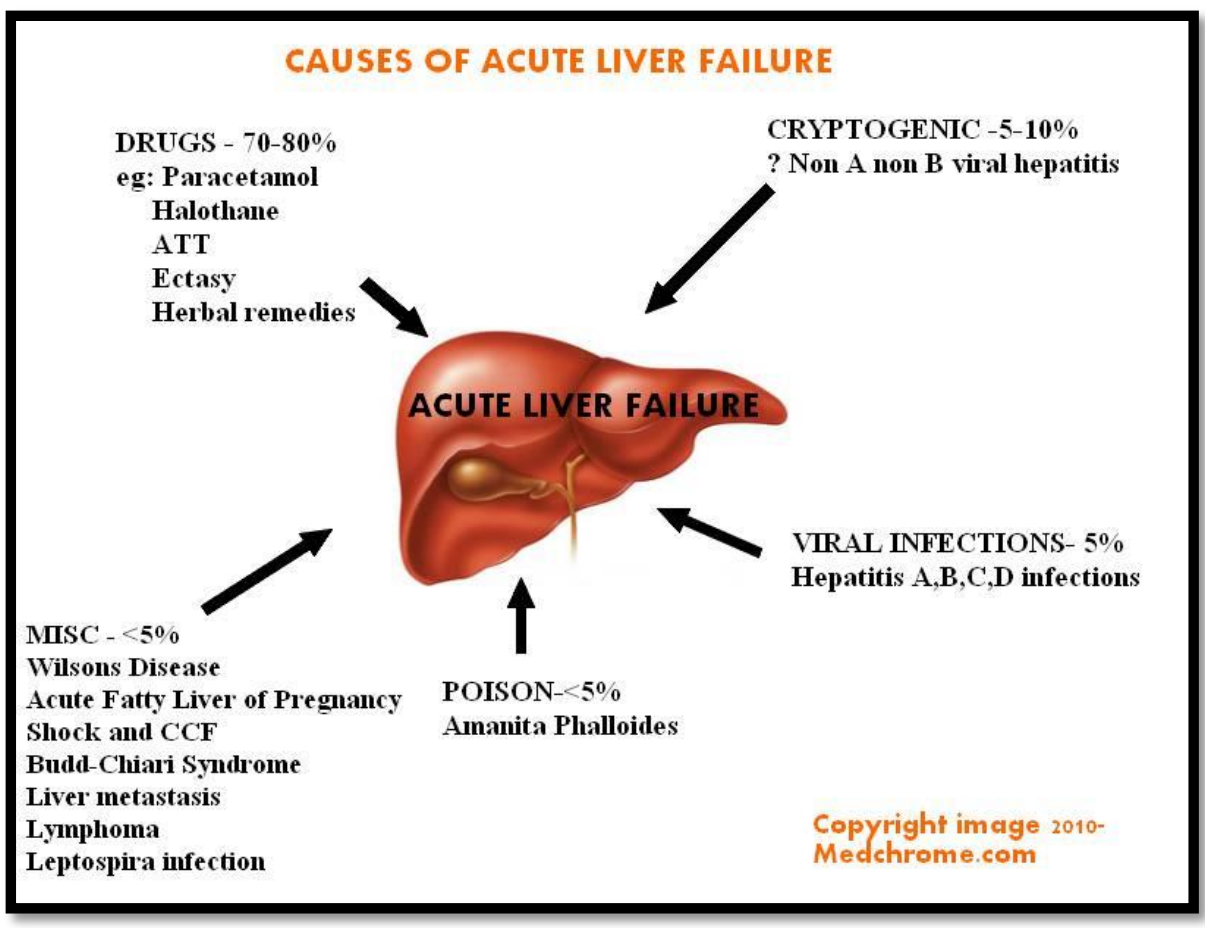

Fig-2: Cause of acute liver failure

\section{Signs \& Symptoms of Hepatotoxicity \& Liver} Failure [39-46]

Hepatotoxicity is an expression used to describe damage caused to the liver by certain chemicals. Common culprits behind this condition are prescription drugs, recreational drugs and even certain herbal supplements and vitamins. It is critical to understand the signs and symptoms associated with hepatotoxicity, as left untreated it can result in liver failure. 
Jaundice

Jaundice is a condition that causes yellowing in the whites of the eyes (sclera) as well as the skin. It is the result of an excessive buildup of bilirubin in the blood. Bilirubin is a yellowish brown chemical in bile, a substance produced by the liver. As the liver loses the ability to effectively break down these chemicals, they store up in the body, which results in jaundice.

\section{Discoloration of urine and feces}

Presence of bilirubin in stool is what gives it its dark color. When it is not properly processed in the liver, it can cause stools to be pale in color. Moreover, this excess buildup of bilirubin can become present in other body fluids such as urine. Urine that is dark in color can be an indication of excess bilirubin, a sign of liver damage.

\section{Chronic itching of the skin}

When the human liver is compromised, a common symptom is extreme itching and irritation of the skin. Less is known about why this phenomenon occurs. Some speculate it is the result of the liver's inability to filter the common toxins and irritants that enter the human body. With nowhere to go, these toxins can sometimes accumulate in the skin, causing the itch.

\section{Swollen legs and/or abdomen}

In severe cases of hepatotoxicity and liver failure, excess fluids can accumulate in the body. Typically, these fluids collect in the legs and cause swelling, a condition known as edema. This fluid can also accumulate in the abdomen, causing swelling and pain. When fluid accumulates in the abdomen, it is known as ascites.

\section{Easy bruising and bleeding}

Of the many jobs the liver is responsible for, one of the most critical is the production of proteins that aid in the clotting of blood. As less of this protein is made available, it becomes easier for the body to become bruised. Frequent nosebleeds are often another symptom of this lack of clotting proteins.

\section{Biochemical Tests Used for the Detection of Hepatic Injury}

Three categories of non invasive laboratory tests are used to identify the type and extent of drug hepatotoxicity based on the presence or absence of specific markers in the blood of exposed individuals. The first category of clinical assays is that used to assess hepatocellular damage leading to liver cell necrosis. Evidence of this type of injury is based on the detection the hepatic transaminases, alanine aminotransferase (ALT), and aspartate aminotransferase (AST). These are not normal components of blood and serve no known function outside the organ of origin. A third specific marker of hepatocellular damage, serum $\mathrm{F}$ protein, has been recently described, although it is not yet as widely used as the transaminases. Based on liver biopsy specimens, chronic ALT elevations in symptomatic patients have also been associated with fatty liver. Infact, nonalcoholic Steatosis has been cited as a very common cause of chronic ALT elevations in the general population. Thus, transaminase elevations are indicative of hepatocellular death and fatty degeneration in particular, but can also be used in conjunction with other serum enzymes for distinguishing on hepatocellular injury as described below. These group of tests includes markers for hepatobiliary (chlolestatic) effects. This type of injury includes biliary obstruction or hepatic infiltrative processes resulting in the retention of bile acids in liver and leading to drug induced jaundice if severe. Serum markers include AlkP from the cell canalicular membrane, 5nucleotidase (5NT), and GGT. However, marked serum AlkP elevations, especially when accompanied by $5 \mathrm{NT}$ or GGT elevations, suggest mechanical bile duct obstruction, primary sclerosingcholangitis, primary biliary cirrhosis, or drug induced hepatitis. Thus, serum enzyme profiles as opposed to individual enzyme changes are used for diagnostic purposes, especially for monitoring hepatobiliary effects. The final category of diagnostic procedures is based upon altered liver function. These are methods tha tmonitor serum albumin, cholesterol, prothrombintime, or serum bilirubin as general indicators of the synthetic and general metabolic capacity of the liver (Fregia, et al., 1994) as opposed to marking some specific toxic injury. The serum bilirubin assay will indicate liver injury; however, elevated serum enzyme assays as described above usually reflect hepatotoxicity earlier. Although drug associated hepatic dysfunction is uncommon in general severely altered liver function, especially those processes leading to coagulation disorders or bilirubin encephalopathy, are indicative of severe hepatic injury [47-50].

\section{Mechanism of Hepatotoxicity caused by Different Agents}

Injure to the liver is not due to the drug itself but to a toxic metabolite ( $\mathrm{N}$-acetyl-p-benzoquinone imine NAPQI or NABQI) which is produced by cytochrome $\mathrm{P}_{450}$ enzymes in the liver. (Wallace J.L., et al., 2004), in overdoses large amount of NAPQI is generated which overwhelm the detoxification process and lead to damage to liver cells. Nitric acid also plays role in inducing toxicity. The mechanisms of hepatotoxicity caused by NSAIDs were documented to be both idiosyncratic and dose dependant. Aspirin and phenylbutazone are associated with intrinsic hepatotoxicity; idiosyncratic reaction has been associated with ibuprofen, sulindac, phenylbutazone, piroxicam, diclofenac and indomethacin. Enlarged liver is a unusual side effect of long term steroid use in children [51, 52].

\section{Carbon tetrachloride}

Liver injury due to carbontetrachloride in rats was first reported in1936 and has been widely and 
successfully used by many investigators. Carbontetrachloride is metabolized by cytochrome $\mathrm{P} 450$ in endoplasmic reticulum and mitochondria with the formation of $\mathrm{CCl}_{3} \mathrm{O}$, a reactive oxidative free radical, which initiates lipid peroxidation. Administration of a single dose of $\mathrm{CCl}_{4}$ to a rat produces, within $24 \mathrm{hrs}$, a centrilobular necrosis and fatty changes. The poison reaches its maximum concentration in the liver within $3 \mathrm{hrs}$ of administration. Thereafter, the level falls and by $24 \mathrm{hrs}$ there is no $\mathrm{CCl}_{4}$ left in the liver. The development of necrosis is associated with leakage of hepatic enzymes into serum. Dose of $\mathrm{CCl}_{4}$ : 0.1 to $3 \mathrm{ml} / \mathrm{kg}$ I.P $[53,56]$.

\section{Paracetamol}

Paracetamol, a broadly used analgesic and antipyretic drug, produces acute liver damage in high doses. Paracetamol administration causes necrosis of the centrilobular hepatocytes characterized by nuclear pyknosis and eosinophilic cytoplasm followed by large excessive hepatic lesion. The covalent binding of $\mathrm{N}$ acetyl-P-benzoquinoneimine, an oxidative product of paracetamol to sulphydryl groups of protein, result in lipid peroxidative degradation of glutathione level and thereby, produces cell necrosis in the liver. Dose of Paracetamol: 1 gm/kg P.O [57].

\section{Oxidative Stress and role of Antioxidants}

Oxidation refers to switch of electrons from a substance to an oxidizing agent. Oxidation reactions consequences in manufacturing of loose radicals which at once begin chain reactions that brings about harm to the dwelling cells. Metabolism in majority of complicated dwelling organisms calls for oxygen for its survival .But, oxygen being, a relatively reactive molecule damages dwelling organisms via way of means of generating reactive oxygen species. These reactive oxygen species produced withinside the dwelling cells consist of hydrogen peroxide (H2O2), hypochlorous acid $(\mathrm{HOCl})$ and loose radicals including the hydroxyl radical $(\bullet \mathrm{OH})$ and the superoxide anion (O2) . The hydroxyl radical is risky and could react hastily and non-mainly with maximum of the organic molecules. This oxidant harms the cells via way of means of beginning chemical chain reactions including lipid peroxidation, or via way of means of oxidizing DNA or proteins. Damage to DNA bring about extreme troubles probable most cancers, if now no longer reversed via way of means of DNA restore mechanisms. Damage to proteins bring about enzyme inhibition, denaturation and protein degradation. During metabolism, the usage of oxygen generates relatively reactive species including the superoxide anion that is produced as a spinoff of numerous steps with inside the electron delivery chain. The discount of coenzyme Q in complicated III, consequences withinside the formation of relatively reactive loose radical as an intermediate (Q•-). This intermediate, being risky consequences in electron "leakage", in which the electrons soar without delay to oxygen and shape the superoxide anion, as opposed to shifting thru the everyday collection of wellmanaged reactions of the electron delivery chain. An antioxidant is a molecule that slows or prevents the oxidation of the molecules. Antioxidants terminate those chain reactions via way of means of disposing of loose radical intermediates and inhibit different oxidation reactions via way of means of being oxidized themselves. As a result, antioxidants are regularly taken into consideration as lowering retailers including thiols, ascorbic acid, polyphenols. Antioxidants are categorized into extensive divisions, relying on whether or not they're soluble in water (hydrophilic) or in lipids (hydrophobic). In general, water-soluble antioxidants react with oxidants withinside the mobileular cytosol and the blood plasma, at the same time as lipid-soluble antioxidants shield mobileular membranes from lipid peroxidation. Although oxidation reactions are important for survivals, they also can be damaging. Hence, flowers and animals hold complicated structures of a couple of sorts of antioxidants, including glutathione, diet $\mathrm{C}$, and diet $\mathrm{E}$ in addition to enzymes including catalase, superoxide dismutase and numerous peroxidases. Low tiers of antioxidants or inhibition of the antioxidant enzymes, reason oxidative strain and can harm or kill the dwelling cells. As oxidative strain is an essential a part of many human sicknesses, the usage of antioxidants in pharmacology is intensively studied, especially withinside the remedy of stroke and neurodegenerative sicknesses. Antioxidants are broadly used as elements withinside the nutritional dietary supplements which will hold fitness and to save you sicknesses including most cancers and coronary coronary heart disease. These compounds can be synthesized withinside the frame or acquired from the diet. The exclusive antioxidants are gift at a extensive variety of concentrations in frame fluids and tissues, a few including glutathione or ubiquinone by and large gift within side the cells, at the same time as others including uric acid are greater flippantly distributed. The movement of an antioxidant for this reason relies upon at the right characteristic of different individuals of the antioxidant system. The volume of safety furnished via way of means of someone antioxidant additionally relies upon on its concentration, its reactivity closer to the unique reactive oxygen species and the fame of the antioxidants with which it interacts $[58,59]$. 


\begin{tabular}{|c|c|c|}
\hline \multicolumn{3}{|c|}{ Antioxidant protection system in biological system $[60,61]$} \\
\hline Endogenous Antioxidants & Dietary Antioxidants & Metal Binding Proteins \\
\hline $\begin{array}{l}\text { - } \quad \text { Bilirubin } \\
\text { - } \quad \text { Thiols, e.g., glutathione, lipoic acid, N- } \\
\text { acetyl cysteine } \\
\text { - } \quad \text { NADPH and NADH } \\
\text { - } \quad \text { Ubiquinone (coenzyme Q10) } \\
\text { - } \quad \text { Uric acid } \\
\text { Copper/zinc and manganese-dependent } \\
\text { superoxide dismutase (SOD), Iron-dependent } \\
\text { catalase \& Selenium-dependent glutathione } \\
\text { peroxidise. }\end{array}$ & $\begin{array}{l}\text { - } \quad \text { Vitamin C } \\
\text { - } \quad \text { Vitamin E } \\
\text { Beta carotene and other } \\
\text { carotenoids and oxycarotenoids, } \\
\text { e.g., lycopene and lutein } \\
\text { - Polyphenols, e.g., flavonoids, } \\
\text { flavones, flavonols, and } \\
\text { Proanthocyanidins }\end{array}$ & $\begin{array}{ll}\text { - } & \text { Albumin (copper) } \\
\text { - } & \text { Ceruloplasmin } \\
& \text { (copper) } \\
\text { - } & \text { Metallothionein } \\
& \text { (copper) } \\
\text { - } & \text { Ferritin (iron) } \\
\text { - } & \text { Myoglobin (iron) } \\
\text { - } & \text { Transferrin (iron). }\end{array}$ \\
\hline
\end{tabular}

\section{CONCLUSION}

The occurrence and incidence of cirrhosis and number one liver most cancers are key to apprehend the weight of liver disorder. They constitute the end-degree of liver pathology and for this reason are indicative of the related mortality. Harmful alcohol consumption, viral hepatitis $\mathrm{B}$ and $\mathrm{C}$ and metabolic syndromes associated with obese and weight problems are the main reasons of cirrhosis and number one liver most cancers in India. Chronic hepatitis B influences principal society population. Each of those 4 principal reasons of liver disorder is amenable to prevention and treatment, lowering the weight of liver disorder in India and saving lives. Further surveys are urgently had to put into effect cost-powerful prevention program and novel remedies to address this problem.

\section{REFERENCE}

1. Saxena, R., Theise, N. D., \& Crawford, J. M. (1999). Microanatomy of the human liverexploring the hidden interfaces. Hepatology, 30(6), 1339-1346.

2. Si-Tayeb, K., Lemaigre, F. P., \& Duncan, S. A. (2010). Organogenesis and development of the liver. Developmental cell, 18(2), 175-189.

3. Lynch, T., Price, A. (2007). Amer. Fam. Physician, 76, 391-6.

4. Dipiro Joseph T., Talbert Robert L., Gary C. Yee, Gary R. Matzke "Pharmacotherapy A Pathophysiologic Approach "Seventh Edition 2008.

5. Jalan, R., Gines, P., Olson, J. C., Mookerjee, R. P., Moreau, R., Garcia-Tsao, G., ... \& Kamath, P. S. (2012). Acute-on chronic liver failure. Journal of hepatology, 57(6), 1336-1348.

6. Gustot, T., Fernandez, J., Garcia, E., Morando, F., Caraceni, P., Alessandria, C., ... \& Zaccherini, G. (2015). Clinical course of acute-on-chronic liver failure syndrome and effects on prognosis. Hepatology, 62(1), 243-252.

7. Moreau, R., Jalan, R., Gines, P., Pavesi, M., Angeli, P., Cordoba, J., ... \& Arroyo, V. (2013). Acute-on-chronic liver failure is a distinct syndrome that develops in patients with acute decompensation of cirrhosis. Gastroenterology, 144(7), 1426-1437.

8. Bajaj, J. S., O'Leary, J. G., Reddy, K. R., Wong, F., Biggins, S. W., Patton, H., ... \& Kamath, P. S. (2014). Survival in infection-related acute-onchronic liver failure is defined by extrahepatic organ failures. Hepatology, 60(1), 250-256.

9. Sarin, S. K., Kumar, A., Almeida, J. A., Chawla, Y. K., Fan, S. T., Garg, H., ... \& Yuen, M. F. (2009). Acute-on-chronic liver failure: consensus recommendations of the Asian Pacific Association for the study of the liver (APASL). Hepatology international, 3(1), 269-282.

10. Jalan, R., Yurdaydin, C., Bajaj, J. S., Acharya, S. K., Arroyo, V., Lin, H. C., ... \& Kamath, P. S. (2014). Toward an improved definition of acuteon-chronic liver failure. Gastroenterology, 147(1), 4-10.

11. Shi, Y., Yang, Y., Hu, Y., Wu, W., Yang, Q., Zheng, M., ... \& Chen, Z. (2015). Acute-on-chronic liver failure precipitated by hepatic injury is distinct from that precipitated by extrahepatic insults. Hepatology, 62(1), 232-242.

12. Nadim, M. K., Kellum, J. A., Davenport, A., Wong, F., Davis, C., Pannu, N., ... \& Genyk, Y. S. (2012). Hepatorenal syndrome: the 8 th international consensus conference of the Acute Dialysis Quality Initiative (ADQI) Group. Critical Care, 16(1), 1-17.

13. Wong, F., Nadim, M. K., Kellum, J. A., Salerno, F., Bellomo, R., Gerbes, A., ... \& Arroyo, V. (2011). Working Party proposal for a revised classification system of renal dysfunction in patients with cirrhosis. Gut, 60(5), 702-709.

14. Kamath, P. S., Wiesner, R. H., Malinchoc, M., Kremers, W., Therneau, T. M., Kosberg, C. L., ... \& Kim, W. R. (2001). A model to predict survival in patients with end-stage liver disease. Hepatology, 33(2), 464-470.

15. Dianzani, M. U., \& Barrera, G. (2008). Pathology and physiology of lipid peroxidation and its carbonyl products. Free radical pathophysiology, 19-38.

16. Singh, D., Cho, W. C., \& Upadhyay, G. (2016). Drug-induced liver toxicity and prevention by 
herbal antioxidants: an overview. Frontiers in physiology, 6, 363.

17. Basra, S., \& Anand, B. S. (2011). Definition, epidemiology and magnitude of alcoholic hepatitis. World journal of hepatology, 3(5), 108.

18. Zeisel, S. H., Da Costa, K. A., Franklin, P. D., Alexander, E. A., Lamont, J. T., Sheard, N. F., \& Beiser, A. (1991). Choline, an essential nutrient for humans. The FASEB journal, 5(7), 2093-2098.

19. Lewis, J. H., Ranard, R. C., Caruso, A., Jackson, L. K., Mullick, F., Ishak, K. G., ... \& Zimmerman, H. J. (1989). Amiodarone hepatotoxicity: prevalence and clinicopathologic correlations among 104 patients. Hepatology, 9(5), 679-685.

20. Floyd, J., Mirza, I., Sachs, B., \& Perry, M. C. (2006, February). Hepatotoxicity of chemotherapy. In Seminars in oncology (Vol. 33, No. 1, pp. 5067). WB Saunders.

21. Boelsterli, U. A., Zimmerman, H. J., \& KretzRommel, A. (1995). Idiosyncratic liver toxicity of nonsteroidal antiinflammatory drugs: molecular mechanisms and pathology. Critical reviews in toxicology, 25(3), 207-235.

22. Lewis, J. H., Ranard, R. C., Caruso, A., Jackson, L. K., Mullick, F., Ishak, K. G., ... \& Zimmerman, H. J. (1989). Amiodarone hepatotoxicity: prevalence and clinicopathologic correlations among 104 patients. Hepatology, 9(5), 679-685.

23. McDonald, G.B., \& Tirumali, N. (1984). Intestinal and liver toxicity of antineoplastic drugs. West. J. Med. 140, 250-259.

24. Zimmerman, M.D., \& Hayman, J. (1976). Clin. Diag. and Manag. By lab. Methods, 17, 217-50.

25. BRECKENRIDGE, A. (1996). A clinical pharmacologist's view of drug toxicity. British journal of clinical pharmacology, 42(1), 53-58.

26. Park, B. K., Pirmohamed, M., \& Kitteringham, N. R. (1992). Idiosyncratic drug reactions: a mechanistic evaluation of risk factors. British journal of clinical pharmacology, 34(5), 377-395.

27. George, D. K., \& Crawford, D. H. (1996). Antibacterial-induced hepatotoxicity. Drug safety, 15(1), 79-85.

28. Black, M. (1987). Hepatotoxic and hepatoprotective potential of histamine (H2)receptor antagonists. The American journal of medicine, 83(6), 68-75.

29. Klaassen, C. D. (Ed.). (2013). Casarett and Doull's toxicology: the basic science of poisons (Vol. 1236, p. 189). New York: McGraw-Hill.

30. Adams, L. E., \& Hess, E. V. (1991). Drug-related lupus. Drug Safety, 6(6), 431-449.

31. Park, B. K., Pirmohamed, M., \& Kitteringham, N. R. (1992). Idiosyncratic drug reactions: a mechanistic evaluation of risk factors. British journal of clinical pharmacology, 34(5), 377-395.

32. Rahmat, J., Gelfand, R. L., Gelfand, M. C., Winchester, J. F., Schreiner, G. E., \& Zimmerman, H. J. (1985). Captopril-associated cholestatic jaundice. Annals of internal medicine, 102(1), 5658.

33. James, L.P., Mayeur, P.R., Hinson, J.A. (2003). Drug Metab. Dispos, 31(12), 1499-506

34. Navarro, V. J., \& Senior, J. R. (2006). Drug-related hepatotoxicity. New England Journal of Medicine, 354(7), 731-739.

35. Watkins, P. B., \& Seeff, L. B. (2006). Druginduced liver injury: summary of a single topic clinical research conference. Hepatology, 43(3), 618-631.

36. Fontana, R. J., McCashland, T. M., Benner, K. G., Appelman, H. D., Gunartanam, N. T., Wisecarver, J. L., ... \& Acute Liver Failure Study Group. (1999). Acute liver failure associated with prolonged use of bromfenac leading to liver transplantation. Liver Transplantation and Surgery, 5(6), 480-484.

37. Buckley, N. A., Buckley, N., Whyte, I. M., O'Connell, D. L., \& Dawson, A. H. (1999). Oral or intravenous $\mathrm{N}$-acetylcysteine: which is the treatment of choice for acetaminophen (paracetamol) poisoning?. Journal of Toxicology: Clinical Toxicology, 37(6), 759-767.

38. Cameron, G. R., Thomas, J.C., \& Karunarathe, W. A.E. (1936). J. Path. Bact, 41, 297

39. Chang, C. C., Petrelli, M., Tomashefski Jr, J. F., \& McCullough, A. J. (1999). Severe intrahepatic cholestasis caused by amiodarone toxicity after withdrawal of the drug: a case report and review of the literature. Archives of Pathology and Laboratory Medicine, 123(3), 251-256.

40. Clampitt, R.B., \& Hart, R.J. (1978). The tissue activities of some diagnostic enzymes in ten mammalian species. J. Comp. Pathol, 88, 607-621.

41. Craxi, A., \& Almasio, P. (1996). Diagnostic approach to liver enzyme elevation. J.Hepatol, 25, 47-51.

42. Cullen, P. (2005). Mechanistic classification of liver injury. Toxicol Pathol, 33, 6-8.

43. Davis, M. (1989). Drugs and abnormal 'liver function tests.' Adverse Drug React. Bull, 139, 520-523.

44. Dawkins MJR. J.Path. Bact. , 1963; 85, 189

45. Dhami, M.S.I., Drangova, R., Farkas, R., Balazs, T., \& Feuer, G. (1979). Decreased aminotransferase activity of serum and various tissues in the rat after cefazolin treatment. Clin.Chem. 25, 1263-1266.

46. Dipiro Joseph T., Talbert Robert L., Gary C. Yee, Gary R. Matzke "Pharmacotherapy A Pathophysiologic Approach "Seventh Edition 2008.

47. Craxi, A., \& Almasio, P. (1996). Diagnostic approach to liver enzyme elevation .J.Hepatol, 25, 47-51.

48. Foster, G.R., Goldin, R.D., \& Oliveira, D.B. (1989). Serum F protein: A new sensitive and specific test of hepatocellular damage. Clin. Chim. Acta, 184, 85-92. 
49. Herlong, H.F. (1994). Approach to the patient with abnormal liver enzymes. Hosp. Pract, 29, 32-38.

50. Hultcrantz, R., Glaumann, H., Lindberg, G., \& SonNilsson, L. (1986). Liveri nvestigation in 149 asymptomatic patients with moderately elevated activities of serum aminotransferases. Sc and. J. Gastro enteral, 21, 109-113.

51. Iancu, T.C., Shiloh, H., Dembo, L. J. (1986). Pediatr. Gastroenterol. Nutr; 5(1), 41-6

52. James LP, Mayeur PR, Hinson JA. Drug Metab. Dispos., 2003; 31(12), 1499-506

53. Cameron, G.R., Thomas, J.C., \& Karunarathe, W.A.E. J. Path. Bact. 1936; 41, 297

54. Dawkins MJR. J.Path. Bact. , 1963; 85, 189

55. Shirwaiker, A., Sreenivasan, K.K., Krishnanand, B. R., Kumar, A.V. (1996). Fitoterapia, 67(3), 200-4.
56. Zimmerman, M.D., \& Hayman, J. (1976). Clin. Diag. and Manag. By lab. Methods, 17, 217-50.

57. Kapur, V., Dillai, K.K., Hussain, S.Z., Balani, D.K. (1994). Ind.J.Pharmacol, 26(4), 301-03

58. Bee Ling Tan. (2018). Antioxidant and Oxidative Stress: A Mutual Interplay in Age-Related Diseases. Front Pharmacol. 2018; 9: 1162.

59. Aurelia Magdalena Pisoschi. (2015). The role of antioxidants in the chemistry of oxidative stress: A review. European Journal of Medicinal Chemistry, 97,$5 ; 55-74$.

60. Dontha, S. (2016). A review on antioxidant methods. Asian J Pharm Clin Res. 9(8): 14-32.

61. Duračková, Z. (2010). Some current insights into oxidative stress. Physiol Res. 59(4): 459-69.

Cite This Article: Lalita Bansal \& Ashish Dhiman (2022). Chronicity of Hepatotoxicity: A Review. East African Scholars J Med Surg, 4(1), 6-14. 